\title{
DETERMINATION OF SCREW ANCHOR CAPACITY IN ULTRA-THIN STEEL FIBER REINFORCED SELF-STRESSING CONCRETE (SFRSSC) FLAT SLABS
}

\author{
Janis Locmanis $^{1}$, Rolands Cepuritis ${ }^{2}$, Bradley J. Pease ${ }^{1}$ \\ ${ }^{1}$ SIA “PRIMEKSS", Latvia; ${ }^{2}$ Norwegian University of Science and Technology, Norway \\ janis.locmanis@primekss.com, rolands.cepuritis@ntnu.no, bradley.pease@ primekss.com
}

\begin{abstract}
Industrial concrete warehouse slabs constructed with steel fibre reinforced self-stressing concrete (SFRSSC), with a moderate to high content $\left(\geq 30 \mathrm{~kg} \cdot \mathrm{m}^{-3}\right)$ of steel fibre reinforcement and expansive cementitious additives, can provide equivalent load bearing capacity as traditional reinforced or unreinforced concrete slabs with a reduced slab thickness. The reduction in slab thickness is possible due to improved flexural capacity of SRFSSC together with a reduced propensity for cracking and curling, common issues in traditional concrete slabs, caused by shrinkage. By reducing the slab thickness, the allowable length of mechanical anchors, commonly embedded in concrete slabs to restrain the racking system, is impacted. Anchors, and accompanying design aids and guidance provided by anchor manufacturers, available in the market are generally produced with traditional concrete slabs with higher thickness in mind. There is generally a lack of guidance and design aids for applications with thinner slabs constructed with SFRSSC. This paper presents data from over 250 pull-out test results of screw-type anchors extracted from SFRSSC slab specimen. The test series varies parameters from both the screws (diameter and length) and the SFRSSC slabs (slab thickness, fibre type/content, and concrete compressive strength). Testing was completed in accordance with relevant European Assessment Documents and results conclude combinations of anchor type and slab details (thickness, fibre type/content, and concrete compressive strength), where equivalent or improved tensile capacity is achieved for screw anchors embedded in SFRSSC.
\end{abstract}

Keywords: steel fibre reinforced concrete, mechanical fasteners, warehouse floors.

\section{Introduction}

Industrial warehouse slabs are commonly used as foundations for racking systems, which are fixed in place by mechanical anchors that are either drilled-in or mechanically or chemically-bonded to the concrete substrate. Engineers typically rely on design aids, provided by anchor manufacturers, in the design of such connections between racking systems and a warehouse floor. These design aids were developed based on testing of slabs constructed with traditional reinforced or unreinforced concrete.

However, more advanced materials are commonly used to construct industrial slabs, including steel fibre reinforced concrete (SFRC) or steel fibre reinforced self-stressing concrete (SFRSSC) [1]; [2], which are typically capable of carrying equivalent load levels as traditional reinforced concrete slabs with reduced slab thickness. Reducing the slab thickness limits appropriate anchor types/lengths and the design aids and guidance from anchor manufacturers typically assume that the concrete substrate consists of traditional concrete mixture design, without steel fibre. Therefore, currently there is a lack of information, guidance, and aids for the design of mechanical anchors embedded in SFRSSC slabs. While there is evidence that the addition of steel fibre to concrete can provide a beneficial impact on anchor performance (see, e.g. [3]; [4]), testing of SFRSSC is not known by the authors. The anchor type investigated here, a Hilti HUS3 screw anchor, has a known performance when embedded in traditional concrete (without fibres), as documented in the European Technical Assessment [5]. However, it is unclear whether it is appropriate to apply characteristic values provided in [5] when anchors are embedded in SFRSSC.

Screw anchor resistance depends on various factors. It is the anchor diameter, thread, embedment, concrete, age of concrete, installation method and other [6]. For the research presented in the current paper, however, a higher focus is given for the SFRSSC contribution to anchor resistance, not excluding data on the other relevant parameters. The main objective of the study by Mohyeddinet. al. [6] was to distinguish failure modes and provide calculation methods for Concrete Capacity Design (CCD) to each failure mode. Their paper [6] emphasizes more than one equation for tensile strength, thus avoiding underestimation or overestimation of the tensile strength what is more important for their tests, considering that there is different and a more repeatable failure mode. Nevertheless, that 
paper [6] states that there is no difference for tensile strength depending on the failure modes and it is pointed out that the conducted research is not applicable to all types of screws and substrate materials.

Another recent paper by Tóth et al. [7] seeks to study SFRC impact on adhesive anchors. Their studies show that fibres have positive influence on load-displacement behaviour of the anchorage and they also propose modified CCD for SFRC. They show that SFRC provides higher fracture energy. As well that SFRC provides more ductile behaviour and crack bridging what provides stronger fixture. Tóth [7] also concludes that there is no large influence on the anchor tensile strength, whereas pure pull-out failure mode is observed, and rather concentrates on achieving cone failure and edge resistance to investigate fibre contribution to strength - for all tests increase was observed from $11 \%$ to $50 \%$. Their research [7] also observed an increased load capacity for anchor groups comparing to single anchor in SFRC. However, these observations could not be applied directly to the current research because of different conditions and the influence of group anchors on thin SFRSSC slabs should be studied separately.

Both of the given previous studies [6;7] have looked into anchor behaviour in concrete specimens with thickness approximately $\sim 200 \mathrm{~mm}$.

The aim of the study presented in this paper is to investigate the basic tension pull-out behaviour in SFRSSC ultra-thin $(90 \mathrm{~mm})$ uncracked concrete using a specific type of screw anchor, with varying diameter and length, and SFRSSC slabs, with varying slab thickness, fibre type and content, and concrete compressive strength. The results obtained in this study are compared to the characteristic values in [5] to assess whether the anchor/SFRSSC slab combination has an equivalent performance as the anchor in a traditional concrete slab. In cases where a substantial reduction in capacity was observed in a studied material combination, that combination is identified as being not optimal.

\section{Materials and methods}

Table 1 provides details on the complete test series, including overview on the anchors tested and on the concrete slabs into which anchors were installed. A total of 49 SFRSSC slabs were cast with varying concrete compressive strength (i.e. concrete class shown in Table 1 per EN 1992-1-1 [8] definitions), slab thickness, fibretype and content,as shown in Table 1. Two fibre types were investigated, HE+1/60 and HE 75/50 hooked-end steel fibres. The HE + 1/60 fibres had a diameter of $1.0 \mathrm{~mm}$, length of $60 \mathrm{~mm}$ and a wire tensile strength of $1500 \mathrm{~N} \cdot \mathrm{mm}^{-2}$, while the HE 75/50 had a diameter $0.75 \mathrm{~mm}, 50 \mathrm{~mm}$ length and $1200 \mathrm{~N} \cdot \mathrm{mm}^{-2}$ wire tensile strength. Hilti HUS3-H screw anchors were used for all tests, with varying anchor diameters and lengths, as shown in Table 1 . The dimensions described in Table 1 are illustrated in Fig. 1(a).

Basic pull-out tension tests were completed for the various combinations described in Table 1 in accordance with applicable European Assessment Documents(EAD) [9] and [10]. Fig. 1(b) shows the pull-out test setup used for testing. Statistical processing of the test results is also done according to the EAD documentation, but is not included in the paper in details. The testing and the results were also assessed by Hilti accredited laboratory.

a)

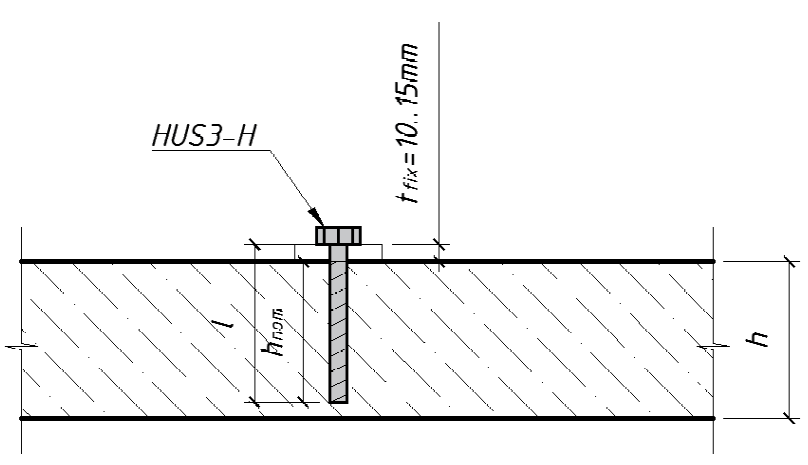

b)

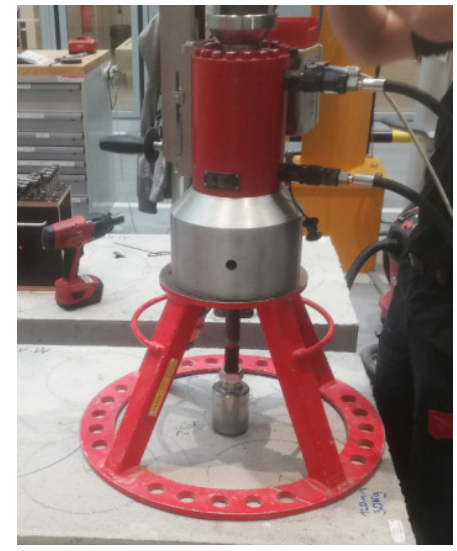

Fig. 1. Schematic of the dimensions presented in Table 2 and photo (a) and photo of the test setup (b) 
Testing series plan of screw anchors embedded in various SFRSSC slabs.

\begin{tabular}{|c|c|c|c|c|c|c|c|c|}
\hline \multirow[b]{2}{*}{ 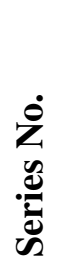 } & \multicolumn{4}{|c|}{ Anchor Details } & \multicolumn{3}{|c|}{ SFRSSC Slab Details } & \multirow{2}{*}{ 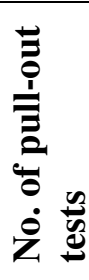 } \\
\hline & Fastener ID & 离 & 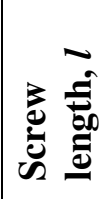 & 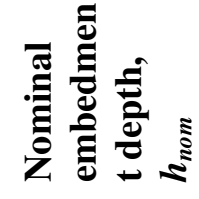 & 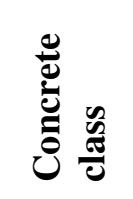 & 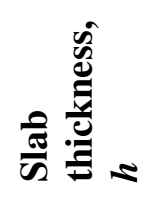 & 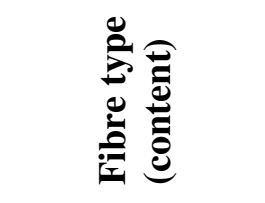 & \\
\hline- & - & $\mathrm{mm}$ & $\mathrm{mm}$ & $\mathrm{mm}$ & - & $\mathrm{mm}$ & $\left(\mathrm{kg} \cdot \mathrm{m}^{-3}\right)$ & - \\
\hline 1 & HUS3-H 14x130 & 14 & 130 & 115 & $\mathrm{C} 30 / 37$ & 160 & $\mathrm{HE}+1 / 60(50)$ & 5 \\
\hline 2 & HUS3-H 14x100 & 14 & 100 & 85 & $\mathrm{C} 30 / 37$ & 160 & $\mathrm{HE}+1 / 60(50)$ & 5 \\
\hline 3 & HUS3-H 10x100 & 10 & 100 & 85 & $\mathrm{C} 30 / 37$ & 160 & $\mathrm{HE}+1 / 60(50)$ & 5 \\
\hline 4 & HUS3-H 8x85 & 8 & 85 & 70 & $\mathrm{C} 30 / 37$ & 160 & $\mathrm{HE}+1 / 60(50)$ & 5 \\
\hline 5 & HUS3-H 14x130 & 14 & 130 & 115 & $\mathrm{C} 25 / 30$ & 120 & HE 75/50 (30) & 5 \\
\hline 6 & HUS3-H 14x100 & 14 & 100 & 85 & $\mathrm{C} 25 / 30$ & 120 & HE 75/50 (30) & 5 \\
\hline 7 & HUS3-H 10x100 & 10 & 100 & 85 & $\mathrm{C} 25 / 30$ & 120 & HE 75/50 (40) & 5 \\
\hline 8 & HUS3-H 10x100 & 10 & 100 & 85 & $\mathrm{C} 25 / 30$ & 90 & HE 75/50 (30) & 5 \\
\hline 9 & HUS3-H 10x85 & 10 & 85 & 75 & $\mathrm{C} 25 / 30$ & 90 & HE 75/50 (30) & 5 \\
\hline 10 & HUS3-H 8x85 & 8 & 85 & 70 & $\mathrm{C} 25 / 30$ & 120 & HE 75/50 (40) & 5 \\
\hline 11 & HUS3-H 8x85 & 8 & 85 & 70 & $\mathrm{C} 25 / 30$ & 90 & HE 75/50 (30) & 5 \\
\hline 12 & HUS3-H 8x75 & 8 & 75 & 60 & $\mathrm{C} 25 / 30$ & 90 & HE 75/50 (30) & 5 \\
\hline
\end{tabular}

\section{Results and Discussion}

Fig. 2 showsthe individual pull-out test results from Series No. 12. The curve shape shown in Fig. 2 , load increasing rapidly to an ultimate load followed by a post-peak softening response, was generally observed for all test series. The ultimate load and the corresponding displacement varied with the size and embedment length of the anchors and with varying concrete strength class and fibre content.For Series No. 12 shown in Fig. 2, the mean was found to be $29.1 \mathrm{kN}$ with a sample standard deviation of $1.79 \mathrm{kN}$.

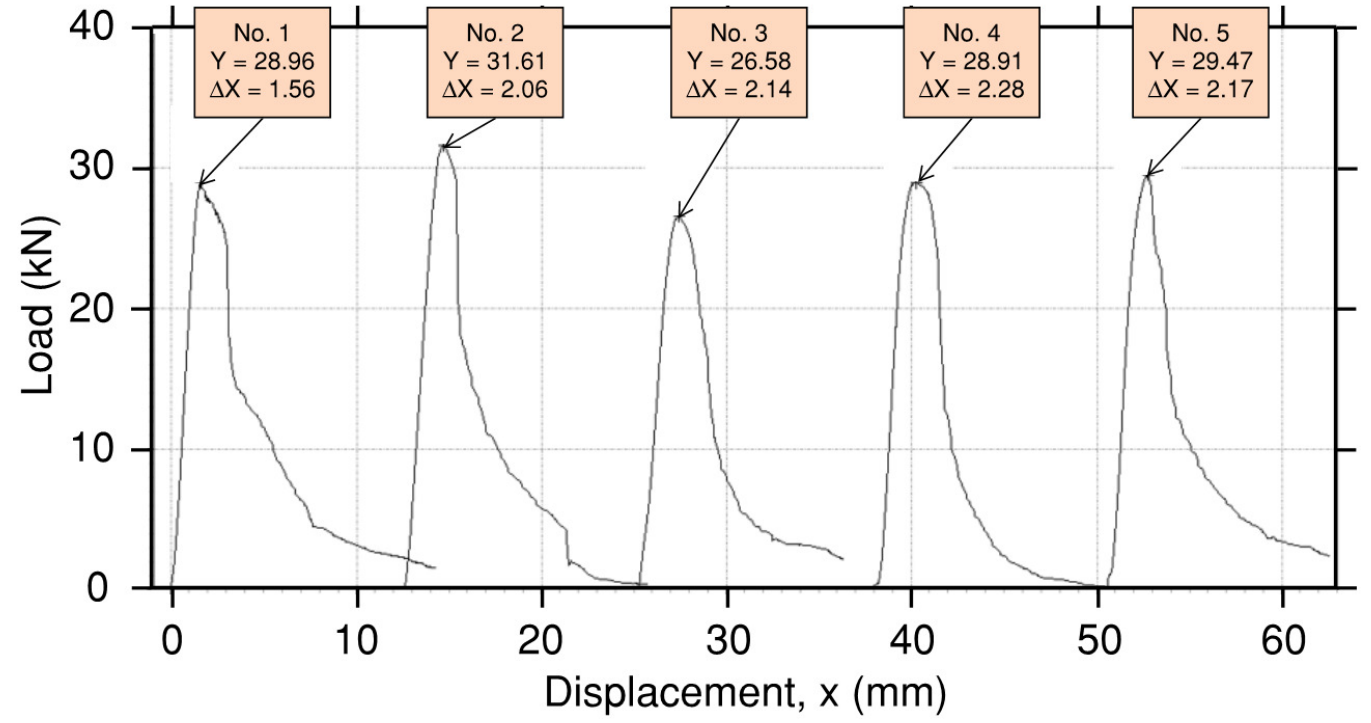

Fig. 2. Typical pull-out strength test result. Results shown are from Series No. 12 with HUS3-H 8x75 anchors embedded in a $90 \mathrm{~mm}$ thick SFRSSC slab with $30 \mathrm{~kg} \cdot \mathrm{m}^{-3} \mathrm{HE} 75 / 50$ steel fibres

Analysis of the results from each test series was completed in accordance with [9] and [10] and based on the recorded mean and sample standard deviation of ultimate loads, and normalizing for the 
actual compressive strength of the SFRSSC slabs, characteristic pull-out strengths were determined for each test series, see Table 3. The determined characteristic strengths were then compared to reported characteristic pull-out strengths for the same Hilti HUS3 anchors embedded in traditional, uncracked concrete from [5]. Table 4 summarizes the concluded outcome of this comparison. It can be seen from the table that the attained results are in line with observations in the reference [7]. It was observed that failure mode for the given tests is a pure pull-out or substrate/bond failure instead of cone failure. But nevertheless, the observed failure mode was observed for a lower base material thickness, smaller edge distance and anchor spacing due to increased concrete fracture energy.

Table 3

Characteristic resistance values for HUS3-H anchors in SFRSSC

\begin{tabular}{|c|c|c|c|c|c|c|c|c|}
\hline Anchor size $\varnothing, \mathbf{m m}$ & \multicolumn{2}{|c|}{8} & \multicolumn{3}{|c|}{10} & \multicolumn{3}{|c|}{14} \\
\hline Anchor length, mm & 75 & 85 & 70a) & 85 & 100 & 75 & 100 & 130 \\
\hline $\begin{array}{c}\text { Embedment depth, } \\
\text { mm }\end{array}$ & 60 & 70 & 55 & 75 & 85 & 65 & 85 & 115 \\
\hline \multicolumn{9}{|c|}{ PrīmX SFRS SC concrete, Concrete thickness, $\mathbf{m m} /$ Fibre dosage, $\mathrm{kg} \cdot \mathrm{m}^{-3}: \mathbf{9 0} / 30$} \\
\hline Tension NRk, kN & 12.0 & 16.0 & 12.0 & -b) & -b) & -b) & $-b)$ & -b) \\
\hline Shear VRk, kN & 19.0 & 22.0 & 14.0 & -b) & -b) & -b) & -b) & -b) \\
\hline \multicolumn{9}{|c|}{ 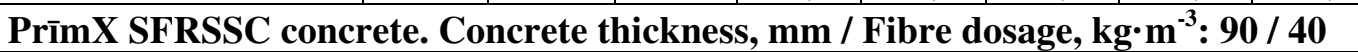 } \\
\hline Tension NRk, kN & 12.0 & 16.0 & 12.0 & -b) & -b) & -b) & -b) & -b) \\
\hline Shear VRk, kN & 19.0 & 22.0 & 13.5 & -b) & -b) & -b) & -b) & -b) \\
\hline \multicolumn{9}{|c|}{ PrīmX SFRSSC concrete, Concrete thickness, mm / Fibre dosage, $\mathrm{kg} \cdot \mathrm{m}-3: 120$ / 30} \\
\hline Tension NRk, $\mathrm{k}$ & 12.0 & 16.0 & 12.0 & 20.0 & 27.8 & 17.5 & $-\mathrm{b})$ & -b) \\
\hline Shear VRk, kN & 19.0 & 22.0 & 13.5 & 30.0 & 34.0 & 35.0 & -b) & -b) \\
\hline \multicolumn{9}{|c|}{ PrīmX SFRSSC concrete, Concrete thickness, $\mathrm{mm} /$ Fibre dosage, $\mathrm{kg} \cdot \mathrm{m}^{-3}:$ / 40} \\
\hline Tension NRk, kN & 12.0 & 16.0 & 12.0 & 20.0 & 27.8 & 17.5 & -b) & -b) \\
\hline Shear VRk, kN & 19.0 & 22.0 & 14.0 & 30.0 & 34.0 & 35.0 & $-b)$ & -b) \\
\hline \multicolumn{9}{|c|}{ PrīmX SFRSSC concrete, Concrete thickness, $\mathrm{mm} /$ Fibre dosage, $\mathrm{kg} \cdot \mathrm{m}^{-3}: 160$ / 50} \\
\hline Tension NRk, kN & 12.0 & 16.0 & 12.0 & 20.0 & 27.8 & 17.5 & 27.3 & 44.4 \\
\hline Shear VRk, kN & 19.0 & 22.0 & 13.5 & 30.0 & 34.0 & 35.0 & 54.5 & 62.0 \\
\hline
\end{tabular}

The gathered data in Table 3 show that the characteristic values for tensions $\left(\mathrm{N}_{\mathrm{Rk}}\right)$ are equivalent to [5] and the shear values $\mathrm{V}_{\mathrm{Rk}}$ are higher.

Table 4

Assessment of equivalence of test results with characteristic values from [5]. Green highlighted cells indicate equivalent performancewith the characteristic value from [5] provided. Red and black highlights indicate not optimal combinations

\begin{tabular}{|c|c|c|c|c|c|c|c|}
\hline Fastener ID & $\begin{array}{c}\text { Screw } \\
\text { diameter }\end{array}$ & $\begin{array}{c}\text { Nominal } \\
\text { embedment } \\
\text { depth, } \mathbf{h}_{\text {nom }}\end{array}$ & \multicolumn{6}{|l|}{ Concrete thickness, mm / Fibre Content, $\mathbf{k g}^{\prime} \mathbf{m}^{-3}$} \\
\hline- & $\mathrm{mm}$ & $\mathrm{mm}$ & $90 / 30$ & $90 / 40$ & $120 / 30$ & $120 / 40$ & $160 / 50$ \\
\hline HUS3-H 8x75 & 8 & 60 & $12 \mathrm{kN}$ & $12 \mathrm{kN}$ & $12 \mathrm{kN}$ & $12 \mathrm{kN}$ & $12 \mathrm{kN}$ \\
\hline HUS3-H 8x85 & 8 & 70 & $16 \mathrm{kN}$ & $16 \mathrm{kN}$ & $16 \mathrm{kN}$ & $16 \mathrm{kN}$ & $16 \mathrm{kN}$ \\
\hline HUS3-H 10x85 & 10 & 75 & & & $20 \mathrm{kN}$ & $20 \mathrm{kN}$ & $20 \mathrm{kN}$ \\
\hline HUS3-H 10x100 & 10 & 85 & & & $1)$ & $1)$ & $1)$ \\
\hline HUS3-H 14x100 & 14 & 85 & & & & & $1)$ \\
\hline HUS3-H 14x130 & 14 & 115 & & & & & $1)$ \\
\hline
\end{tabular}

1) Pull-out failure is not decisive, per [5]. 
The cases, where an equivalent anchor performance in the SFRSSC slabs was observed, are indicated by green-coloured cells in Table 4. The value presented in the green-coloured cells is the reported characteristic pull-out strength from uncracked concrete, from [5], which is considered appropriate for use in the indicated anchor/slab combination. Red highlighted and blacked-out cells in Table 4 indicate situations, where the pull-out strength was reduced and the anchor/slab combination is incompatible, respectively. These combinations are not recommendable. Table 4 , therefore, provides a design aid to 1) allowing for selection of viable anchor types based on the thickness and fibre content of a SFRSSC slab and 2) understand whether the characteristic values for pull-out strength from uncracked concrete in [5] may be applied for Hilti HUS3 screw anchors embedded in SFRSSC slabs.

\section{Conclusions}

Conclusions from the reported investigation into pull-out tensile testing of Hilti HUS3 screw anchors, embedded in steel fibre reinforced self-stressing concrete (SFRSSC), include:

1. SFRSSC allows for a lower base material thickness for the same type anchor compared to traditional concrete and SFRC due to better material local durability against spalling and braking, thus reducing the slab thickness to minimum. The reduced thicknesses is permitted, when construction slabs from SFRSSC do not harm an engineer's ability to select appropriate anchors for use with racking systems or other items fixed to the slab.

2. The anchor pull-out strengths for screw anchors embedded in SFRSSCare typically consistent or improved, compared to reported results for the same screw anchors embedded in traditional, uncracked concrete. Therefore, it is not anticipated that there would be issues (related to pull-out tensile strength considerations) when anchoring racking systems to SFRSSC slabs, while the number and spacing of anchors is subject to appropriate design and installation.

\section{Acknowledgements}

In accordance with the contract No. 1.2.1.1/18/A/007 between "VMKC" Ltd. and the Central Finance and Contracting Agency, the study is conducted by "Primekss" Ltd. with support from the European Regional Development Fund (ERDF) within the framework of the project "Competence centre of smart materials and technologies".

\section{References}

[1] ACI Committee 544, ACI 544.6R-15 - Report on Design and Construction of Steel FiberReinforced Concrete Elevated Slabs, American Concrete Institute, 2015, 38 pp.

[2] Destrée X., Pease B. Reducing CO2 Emissions of Concrete Slab Constructions with the PrimeComposite Slab System, American Concrete Institute (ACI) Special Publication 299, pp. 112, 2015.

[3] Kurz, Thiele, Schnell, Reuter, Vitt - Tragverhalten von Dübeln in Stahlfaserbeton. Bautechnik 82012, S.545-552

[4] Randl N., Gusella O. Tragverhalten von Verbundankern in hoch- und ultrahochfestemBeton Beton- und Stahlbetonbau 106 (2011), Vol 8. pp. 561-573

[5] European Technical Assessment, ETA-13/1038 - Hilti screw anchor HUS322 July 2019, 30 pp.

[6] Mohyeddin A., Emad F. Gad, Jessey Lee, Failure modes and tensile strength of screw anchors in non-cracked concrete, Construction and Building Materials 221 (2019) 501-513.

[7] Tóth M., Bokor B., Sharma A. Anchorage in steel fiber reinforced concrete - concept, experimental evidence and design recommendations for concrete cone and concrete edge breakout failure modes, Engineering Structures 181 (2019) 60-75.

[8] EN 1992-1-1:2004 + A1:2014, Eurocode 2: Design of concrete structures - Part 1-1: General rules and rules for buildings, 2004.

[9] European Organization for Technical Assessment, European Assessment DocumentEAD33001100-0601 - Mechanical Fasteners for use in Concrete, October 2016.

[10]European Organization for Technical Assessment, European Assessment Document EAD 330232-00-0601 - Adjustable Concrete Screws, March 2015. 